\title{
TECHNOLOGIES FOR PREPARING FUTURE PHYSICAL EDUCATION TEACHERS FOR PROFESSIONAL ACTIVITIES ON THE BASIS OF SPORT COACHING Akhmedova Sarvinoz Azatovna ${ }^{1}$
}

\author{
${ }^{1}$ Senior teacher of Navoi State Pedagogical Institute \\ Navoi, Uzbekistan
}

Email:axmedovasavinoz19841012@mail.ru

\begin{abstract}
Suggestions and recommendations on the preparation of future physical education teachers for professional activities on the basis of sports coaching are given in this article.

Keywords: physical training, sports, professional activities, coaching, educational technology.
\end{abstract}

\section{INTRODUCTION}

Improving the knowledge, skills and abilities of students of higher education institutions around the world and the country, the development of intellectual and physical maturity, improving the quality of education, its humanization, the introduction of health-improving technologies to subjects in education, continuity, ensuring developmental and socializing goals, experts, in particular, the tasks of increasing the creativity of physical education teachers are leading.

At the same time, the existence of a number of systemic problems and shortcomings in the organization of physical training and sports hinders the improvement of the professional activity of physical education teachers in this area. In particular: the lack of an effective integrated system of physical training and sports management in the field does not provide adequate coordination of the activities of government agencies and other organizations in this area, the popularization and promotion of healthy lifestyles; the lack of a concept for the development of physical education and sports coaching in the medium and long term, defining specific tasks and targets in the field of mass sports, as well as high sports achievements; imperfect interaction of higher education institutions with the non-governmental sector on the creation of modern material and technical base and infrastructure of sports in partnership; training of physical education teachers and the lack of innovative research and methodological developments in their medical care, standards that meet modern requirements and others. Therefore, everyone wants to reach the highest peaks in their lives, to be in harmony with nature, environment and being. Human success brings him joy and success, but not everyone achieves both financial and social success at the same time. A coach pedagogue and psychologist can help to overcome obstacles in a person's life, to guide him in the right direction, to help him find a solution to a problem. The sports coach teaches each athlete to overcome obstacles in their lives and activities, to develop their achievements in the field of physical training, and to easily solve their failures. Therefore, the development of sports coaching qualities in future physical education teachers is a requirement of today.

\section{LITERATURE REVIEW}

On the history, traditions, methods and directions of sports development in Uzbekistan by F.Kerimov, Sh.Kh.Khonkeldiev, J.M.Tashpulatov, U.I.Ibrokhimov, A.N.Abdiev; Issues of modern organization of physical education and training of future personnel with scientific potential by K.M.Makhkamjanov, I.A.Kushbakhtiev, L.R.Ayrapetyants, T.S.Usmonkhodjaev, S.S.Khodjaev, K.Alimov; Research on the development of national sports, the design of sports clubs, the organization of trips is reflected in the research of H.Kholdarov, R.Abdumalikov, R.A.Kasimov, A.Abdullaev, A.K.Atoev, J.Nurshin, R.Salomov.

Scientists from the Commonwealth of Independent States: In L.S.Podimova, M.I.Morozova, E.V.Rodkina, Yu.I.Rudinova, Z.R.Safina, L.T.Chernova, A.Chesnokov, A.M.Voronin, V.P. Kvasha, N.V.Konoplina, L.G.Rodionova, M.V.Klarin, V.Bespalko, I.V.Shtix, O.Xomerikis' scientific works issues such as the design of the educational process on the basis of pedagogical technologies, the organization of modern person-centered classes through interactive methods, ensuring the active participation of students in physical training classes are studied.

Foreign scholars: M.O.Maxouny, W. Smith (UK), P.Metyo, J.Holmes, P. Scott, I. Rapoport (USA), Dun Shi Chang (China), Charelli Graceo Rini, Sandra Melinder (Malaysia) studied stabilization of mental fitness of athletes, psychological aspects of student socialization in the process of physical training, educating young people through exercise, problems such as improving physical qualities.

In the dissertation named "Professional training of the future teacher of physical culture in the process of pedagogical practice" of Mikhailova Tatyana Alexandrovna for the degree of Candidate of Pedagogical Sciences, the process of modernization of professional training of specialists in the field of physical culture 
and sports is in line with the general strategy of education policy at the present stage, the first task of which is to ensure quality education, its compliance with individual, social and state needs are described. Continuing the author's opinion, he notes that the problems of professional training of physical education teachers have decreased in the context of severe globalization and notes that this does not serve to ensure the proportionality of the students mentioned in the concept of education. Scholar woman at her work: "This situation does not allow the integration of physical culture and sports, prevents the understanding of the phenomenon of physical culture and sports, the formation of a qualitative and purposeful base of worldview of future physical education teachers" [1], she admits.

In the dissertation named "Formation of professional flexibility of representatives of pharmaceutical companies by coaching technology" of Yastreb Olga Viktorovna for the degree of Candidate of Pedagogical Sciences, the issues of formation of professional flexibility of representatives of pharmaceutical companies on the basis of coaching services are reflected, in which the scientist recognizes that coaching technologies are an important component of professional and personal development of specialists in this field. According to the scientist, some aspects of this problem have only been the subject of research in some scientific developments and pamphlets. As noted in this dissertation, a single interpretation of the concept of "professional flexibility" has not yet been developed. Qualitative and professional flexibility of the society, both personally and professionally, as well as effective methods of creating professional flexibility for these specialists are not sufficiently developed in pedagogical theory and practice, and there is a great need for pharmaceutical companies to use coaching services. Continuing her opinion, O.V.Yastreb studied some controversial issues in the formation of professional flexibility of representatives of pharmaceutical companies on the basis of coaching services. These are: the importance of the formation of professional flexibility of representatives of pharmaceutical companies and the lack of methodological development of the mechanism for its implementation in the process of professional development; the ability to shape the professional flexibility of representatives through the inefficient use of coaching technology and the system of in-service training of employees of their pharmaceutical companies and others [2]. In addition to the scholar woman's opinion, it should be noted that there is a need to use coaching services in educational institutions in scientific literature and developments.

\section{MAIN PART}

Identifying and analyzing problems in the development of pedagogical activity to prepare future physical education teachers for professional activities on the basis of sports coaching, as well as improving their knowledge of innovative educational technologies, creating conditions based on innovative forms, methods and means of teaching, pedagogical competence and creative approach to education are considered important.

It is known that technology (Greek "techne" - skill, art, "logos" - concept, doctrine) - the organization of certain processes (production, social, economic, etc.) at the level of high skill, art.

Educational technology (Eng. "An educational technology") - the organization of the educational process at a high level of skill, art [3]. Therefore, the technology of training physical education teachers for future professional activities on the basis of sports coaching is the general content of the process of achieving the goals of education, that is, the gradual implementation of the pre-designed educational process on the basis of an integrated system, the development of specific methods, techniques and means to achieve a specific goal, effective use and high level of management of the educational process. In this regard, during our experimental research (2017-2020) Navoi State Pedagogical Institute, Samarkand, Bukhara universities' faculties of physical education 580200 - sports activities (by type of activity), 5410900 - vocational education, sports activities (by type of activity), 5310400 - we have tried to train specialists in the field of sports psychology, that is to say, future physical education teachers, to carefully develop the methodological development of training that will encourage them to work effectively in the future and we have begun to focus on educational technology in relation to their activities, to create the necessary conditions for students to independently master the teaching materials, taking into account their individual and joint activities with the teacher. It is known that the theory of pedagogical technology has been based on the second half of the last century, but it is clear that there are different approaches to the concept of "pedagogical technology". In particular, the pedagogical scientist V.P.Bespalko describes pedagogical technology as "a project of a specific pedagogical system that can be applied in practice" and focuses on the preliminary design of the educational process [4]. Therefore, based on the fact that "pedagogical technology is a consistent method of creating, implementing and identifying all processes of teaching and learning in technical and human factors, through their joint efforts" (UNESCO), we aim to train future physical education teachers as well as we have started to develop training technology based on sports coaching for future professional activities. In essence, this technology is programmed in accordance with the division of time and is designed to represent a clearly defined system of tasks of all stages and parts of the pedagogical process, which is scientifically based and ensures the achievement of the expected result.

Taking into account the above, we have developed 6 stages of professional training of future physical education teachers on the basis of sports coaching. The tasks of all components and parts of the pedagogical process, ensuring the achievement of the expected result at these stages, are designed to represent a clearly 
defined system. At the same time, the central problem of educational technology based on sports coaching is to ensure the achievement of educational goals through the development of the learner's personality. 6 stages of preparation of future physical education teachers for professional activity on the basis of sports coaching have been developed (Look at the table 1).

6 stages of professional training of future physical education teachers on the basis of sports coaching (based on copyright)

\begin{tabular}{|l|l|}
\hline $\begin{array}{l}\text { Preparation of future physical education teachers } \\
\text { for activities on the basis of sports coaching }\end{array}$ & \multicolumn{1}{|c|}{ Table 1. } \\
\hline 1. Design thinking & The process of creative problem solving \\
\hline 2. Empathy & $\begin{array}{l}\text { Consider the interrelationships between professional } \\
\text { activity and reflection }\end{array}$ \\
\hline 3. Concentration of attention & Develop selected problem-solving skills in coaching \\
\hline 4. Generation of ideas & Summarize ideas on the problem \\
\hline 4 (a). Choosing an idea & Choosing the main idea \\
\hline 4 (b). Prototyping an idea & $\begin{array}{l}\text { To develop skills in the formation of physical } \\
\text { qualities in future students }\end{array}$ \\
\hline 5. Test & $\begin{array}{l}\text { To develop skills to find solutions to specific } \\
\text { problems in the field of physical training and sports }\end{array}$ \\
\hline 6. Result & Achieving the specified result \\
\hline
\end{tabular}

This picture shows 6 stages of preparation of future physical education teachers for professional activity on the basis of sports coaching, which reflects the importance of developing design thinking and rational solution of problem situations in the preparation of future physical education teachers for professional activity on the basis of sports coaching. In the process of education organized in these 6 stages, future physical education teachers will develop skills to analyze the causes and consequences of problematic situations, to find solutions in sports, to form physical qualities in future students. They also develop coaching skills to solve the chosen problem, to find a solution to the problem.

It is known that "the idea of technologicalization of the education system first appeared in Western Europe and the United States at the beginning of the last century at a time when there was a social movement to reform the education system, increase the efficiency of education, create certain conditions for socialization. This idea was based on the introduction of the concept of "pedagogical technique" ("educational technique") in the educational process in the 30s [5].

It is expedient to widely use modern forms and methods of training of future physical education teachers in their professional activity on the basis of sports coaching [6]. Because this is high efficiency is achieved in the educational process through the use of modern forms and methods of teaching. In choosing the forms of education: based on the auditorium, sports ground, gyms, ice arenas, motorsports and others, it is necessary to organize the educational process.

The choice of teaching methods is based on the content of the disciplines of physical culture and sports and the didactic function of each lesson. While maintaining the traditional form of teaching physical training, enriching it with methods that activate the activities of various learners leads to an increase in the level of mastery of students. To do this, high efficiency can be achieved through the rational organization of training, the interest of students by the teacher, the choice of methods and means in accordance with the content of the studied material [7].

In the development of the level of mastery, practical skills and abilities of future physical education teachers through interactive teaching methods, it is advisable to use methods that activate and encourage independent thinking, to achieve high efficiency in the educational process "student-student", "studentteacher" appropriate [8].

"Brainstorming”, "Creative essay writing”, "6 colored hats”, “Open saw”, "Swat analysis”, "Confusing chains", "Icebreakers", "Problem situation", Mental attack" methods in preparing future physical education teachers for professional activity on the basis of sports coaching can be used effectively. When these methods are used, the educator encourages the learner to actively participate [9, 10]. The learner is actively involved throughout the entire process. The benefits of interactive teaching methods are as follows: reading and learning with higher educational effectiveness; high level of motivation of the learner; - taking into account previously acquired knowledge; supporting the initiative and responsibility of the students; learn by doing in practice; creating conditions for bilateral feedback in the field of coaching.

Below we will get acquainted with the content and stages of use of interactive teaching methods, which are widely used in training sessions. "mental attack" is a method of gathering free ideas and feedback by learners on a problem and to come up with a solution through them. There are written and oral forms of the "mental attack" method. Each student expresses his / her opinion orally to the question asked by the educator in oral form.

Prospective physical education teachers explicitly and concisely prohibit their answers. In the written form, students write their answers to the question on paper cards in a short and visible way. The answers are 
fastened to the board (using magnets) or to the "pin board" board (using needles). In the written form of the method of "mental attack" it is possible to group the answers according to certain characteristics. When used properly and positively, this method teaches a person to think freely, creatively, and non-standardly. When using the "mental method" method, it is possible to involve all learners, including developing a culture of communication and discussion in future physical education teachers.

Future physical education teachers develop the ability to express their ideas not only orally but also in writing, the ability to think logically and systematically. Failure to evaluate the opinions expressed leads to the formation of different ideas in learners. This method serves to develop creative thinking in learners. The "problem situation" method is a method aimed at developing students' skills in analyzing the causes and consequences of problem situations in the field of coaching and finding solutions to them. The complexity of the problem selected for the "problem situation" method should correspond to the level of knowledge of future physical education teachers in the field of sports coaching. They need to be able to find a solution to the problem, otherwise when they fail to find a solution, it brings to learners to lose their interest and lose their self-confidence. When using the "problem situation" method, students learn to think independently, analyze the causes and consequences of the problem, find a solution. For example, issues which are including such as state registration of business activities in the field of sports coaching, obtaining various permits and resolving problematic situations in many other service procedures are important for future physical education teachers. Here are the advantages of the "Problem Situation" method: develops independent thinking skills of future physical education teachers; learn to find the cause, effect, and solutions of a problem in the field of coaching; a good opportunity is created to assess the knowledge and skills of learners; students learn to analyze opinions and outcomes, paving the way for awareness of issues related to the rights and legitimate interests of sports coaching subjects.

\section{ANALYSIS AND RESULTS}

Forms and results of control of knowledge of future physical education teachers in physical education classes were studied and analyzed during the experimental research. Experimental and control groups were selected in the experimental areas to analyze the research problem in depth, compare the results. That is to say, 175 future physical education teachers from Samarkand State University, 175 from Bukhara State University and 291 from Navoi State Pedagogical Institute were involved in the experimental sites. A total of 541 prospective physical education teachers and 137 professors participated in the research. Initially, in the mathematical and statistical analysis of the results obtained by various empirical methods in the experimental work, the average mastering rate of the control and test groups was determined and their relative mastery and average difference coefficients were compared. In order to more accurately compare the mastery indicators, the coefficients of variation, sample variances, standard deviations of the control and test groups were calculated and conclusions were drawn. In order to show the effectiveness of the sample distributions of control and test groups, the results were analyzed on the basis of K. Pearson's criterion $x^{\wedge} 2$ (xi square) and appropriate conclusions were drawn. A statistical analysis of the results of the final tests conducted in the test and control groups was conducted when the technologies for the preparation of future physical education teachers for professional activities based on the use of sports coaching were introduced into pedagogical practice. Respondents from universities participated for the experimental sites. To assess the statistical value of the difference in the level of professional pedagogical skills of students of the experimental and control group, the average level of pre-experiment and post-experimental readiness was calculated using the method of double-choice mathematical-statistical method of Student and Pearson. The calculation showed that the average mastering rate of the experimental group was higher than that of the control group, that is to say, which was increased by $13 \%$.

\section{CONCLUSION}

In short, in today's globalization, a wide range of information is coming in and covering a wide range to the social life of our country rapidly. Rapid reception of information, their analysis, processing, theoretical generalization, summarization should be considered as a component of the organization of future pedagogical activity for future teachers. Therefore, the use of interactive and sports coaching technologies in the educational process serves to positively address the above-mentioned topical issue.

In preparing future physical education teachers for professional activities on the basis of sports coaching, it is necessary to develop and implement a system of sports coaching strategies aimed at training for professional activities, to determine their effectiveness pedagogical system in this direction and its didactic support (methodical manuals, recommendations, system of didactic tasks) and on the basis of sports coaching of physical education teachers, pedagogical system of their preparation for professional pedagogical activity (participatory, cognitive activity management, research, openness, continuity) and its didactic support (pedagogy, psychology, physiology, valeology, computer science on the basis of students' information on various electronic media), future physical education study of the state requirements for the content and quality of professional training of teachers on the basis of sports coaching and improvement on the basis of a differentiated approach. As a result, when studying the conditions of preparation of future physical education teachers for professional activity on the basis of sports coaching, the importance of the content of education, selected principles, stages of training and methods and means applied to this process was identified. Also, 
deentological factors in sports coaching determine the high spiritual and moral development of the future physical education teacher and entrepreneurship in interpersonal relationships reflects the pedagogical conditions associated with collective resilience, also it has become clear that the above-mentioned method will be effective for future physical education teachers in solving a specific problem situation on the topic mentioned in the curriculum.

Thus, the need to improve the system of professional training of future physical education teachers on the basis of sports coaching was scientifically substantiated in order to determine the purpose of the study in the research. In order to prepare future physical education teachers for professional activities on the basis of sports coaching, their motivation, interests and mental operations were taken into account: a system of performing mental operations such as analysis, synthesis, comparison, generalization, inference has been identified. The mechanism for the formation of creative thinking in students on the basis of coaching technologies has been improved.

\section{REFERENCES}

[1]. Mikhailova T.A. Professional training of the future physical culture teacher in the process of pedagogical practice // Abstract of the dissertation for the degree of candidate of pedagogical sciences. Chelyabinsk, 2004. - 24 p.

[2]. Yastreb O.V. Formation of professional flexibility of representatives of pharmaceutical companies by means of coaching technology // Abstract of the thesis for the degree of candidate of pedagogical sciences. - Moscow, 2018. - 28 p.

[3]. Muslimov N., Usmonboeva M., Sayfurov D., Turaev A. Innovative educational technologies // Educational-methodical manual. - Tashkent, 2015. - 208 p.

[4]. Bespalko V.P. The components of pedagogical technology. - Moscow: Pedagogy, 1989. - 192 p.

[5]. Sayidahmedov N. New pedagogical technologies. - Tashkent: Finance, 2003. - 172 p.

[6]. 10. Usmonkho'jaev T.S., S.G. Arzumanov, V.A. Qodirov. Physical education. Textbook for professional colleges. - T.: Oqituvchi, 2003. - 208 p.

[7]. Abdullaeva Sh. A. Methods for diagnosing the level of training of athletes. - Tashkent: Kamalak, 2002. - $134 \mathrm{p}$.

[8]. Abdumalikov R., Ashmarin B. A. Biomechanical indicators of future athletes. - Toshkent: Physical culture, 2009. - $231 \mathrm{p}$.

[9]. Avliyakulov N.Kh., Musaeva N.N. Pedagogical technology // Textbook for higher education institutions // - Tashkent: ChoMponNMIU, 2012. - 208 p.

[10]. Sayidahmedov N. New pedagogical technologies. - T.: Finance, 2003. - 172 p.

[11]. Irgashevich, D. A. (2020). Development of national network (tas-ix). ACADEMICIA: An International Multidisciplinary Research Journal, 10(5), 144-151. Article http://dx.doi.org/10.5958/2249-7137.2020.00254.2 